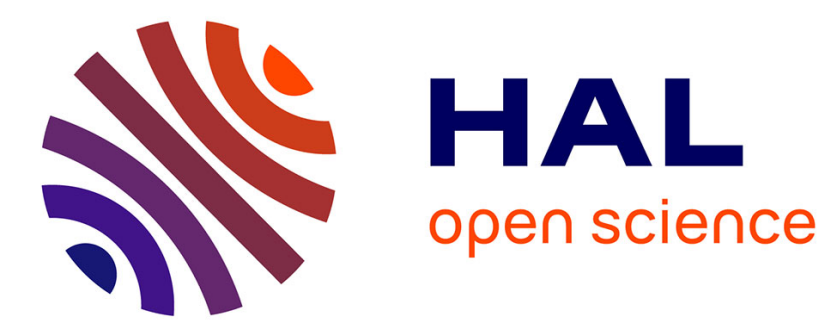

\title{
Conductivity studies on solid polymer electrolytes
}

\author{
C. Sequeira, M. Plancha, L. Araújo
}

\section{To cite this version:}

C. Sequeira, M. Plancha, L. Araújo. Conductivity studies on solid polymer electrolytes. Journal de Physique IV Proceedings, 1994, 04 (C1), pp.C1-17-C1-35. 10.1051/jp4:1994102 . jpa-00252444

\section{HAL Id: jpa-00252444 https://hal.science/jpa-00252444}

Submitted on 1 Jan 1994

HAL is a multi-disciplinary open access archive for the deposit and dissemination of scientific research documents, whether they are published or not. The documents may come from teaching and research institutions in France or abroad, or from public or private research centers.
L'archive ouverte pluridisciplinaire HAL, est destinée au dépôt et à la diffusion de documents scientifiques de niveau recherche, publiés ou non, émanant des établissements d'enseignement et de recherche français ou étrangers, des laboratoires publics ou privés. 


\title{
Conductivity studies on solid polymer electrolytes
}

\author{
C.A.C. SEQUEIRA, M.J.C. PLANCHA and L.P.S. ARAÚJO \\ Instituto Superior Técnico, Av. Rovisco Pais, 1096 Lisboa codex, Portugal
}

\begin{abstract}
This thematic lecture adaresses electrochemical conductivity techniques for the study of solid polymer electrolytes. Types of conductivity are discussed first, followed by an outline of the features, applicability, and validity of $D C$ and $A C$ conductivity measurements. Techniques for the identification of the individual species responsible for conduction are then briefly reviewed.

Rés umé

Cette étude aborde des méthodes de mesure de conductivité électrique des électrolytes polymères solides. On considère $d^{\prime}$ abord la conductivité ionique et électronique, par des mesures en courant continu et en courant alternatif. La détermination des nombres de transport pour qu' on puisse avoir des informations plus complètes sur les espèces responsables de la conduction est examinée ultérieurement.
\end{abstract}

\section{Introduction}

Progress to date in solid-state ionics is largely the result of developments in two categories of materials: insertion compounds and fast ionic conductors (1). Polymer electrolytes represent the newest class of ionic solids. They contrast sharply with the usual solid ionic materials based on ceramics, glasses, or inorganic crystals with respect to the mode of charge transport (polymer electrolytes transport charge well only above their glass transition temperature) and the value of the ionic conductivity, which is of the order of 100 to 1000 times lower than for the latter materials. This arawback is compensated by a number of factors. For example, the polymer electrolytes can be formed into very thin films of large surface area giving

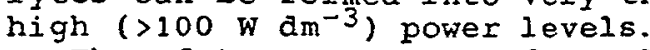

The future prospects for polymer electrolytes look promising because it has been appreciated that they form an ideal medium for a wide range of electrochemical processes. Other than primary and secondary batteries (2) and ambient temperature fuel cells, practical applications for polymer electrolytes that are under consideration include electrochromic devices, modified electrode/sensors, solidstate reference electrode systems, supercapacitors, thermoelectric 
generators, high-vacuum electrochemistry, and electrochemical switching.

A polymeric electrolyte intended for use in a battery, sensor or electrochromic device must have adequate ionic conductivity for the intended purpose, together with negligible electronic conductivity if self-discharge on standing is to be avoided. It may also be necessary to obtain detailed information on the dependence of conductivity on temperature and/or pressure if the proposed operating conditions are wide ranging. The nature of the conducting species, ions, electrons or electron holes, in a polymer electrolyte may be important in understanding the conduction mechanism and the structure/conductivity relationships in this class of materials. For a different reason, namely compatibility with the intended electrode reactions, speciation into cationic, anionic and ion-pair conductivity may be necessary when characterising a polymeric electrolyte.

It is therefore clear that the conductivity of a polymer electrolyte is an important parameter, and this thematic lecture addresses electrochemical conductivity techniques for the study of solid polymer electrolytes. Types of conductivity are discussed first, followed by an outline of the features, applicability, and validity of $D C$ and $A C$ conductivity measurements. Techniques for the identification of the individual species responsible for conduction are then briefly reviewed.

It should be pointed out that the choice of terminal conditions (electrode materials) may influence the above parameters and therefore special attention must be paid to the type of terminal or electrode. If the electrodes are "reversible" or "non-blocking", that is are made of atoms that can be transformed into the conducting ions, charge transfer takes place at the interfaces and this process affects the measurements. If the electrodes are "blocking", that is are made of an incompatible material such that ions cannot cross the interface, then a double-layer capacitance is set up. The other reason that the electrode-electrolyte interface affects the measurements is that the contact between electrode and electrolyte is imperfect. Either component may possibly be coated with a resistive layer of impurity on the surface. Even if this is not the case, the current carrying pathway will be discontinuous and additional impedance, analogous to a grainboundary, will be encountered.

\section{Contributions to Conductivity}

The total conductivity, $\sigma$, is the sum of electronic, $\sigma_{e l}$, and ionic, $\sigma_{i}$, contributions:

$$
\sigma=\sigma_{e l}+\sigma_{i}
$$

Consider a polymer electrolyte of the type $P_{n}: M x$ (where $P$ is the structural repeat unit of the polymer chain and $n$ is the stoichiometric ratio of structural repeat units to formula units of $s a l t ~ M(X)$. Furthermore, assume the valence of $M$ and of $X$ is plus one and minus one, respectively. An average value of the electrical conductivity can be obtained by measuring the ac conductivity of $P_{n}$ : MX between two inert electrodes and with an inert gas passing over the sample. Alternatively, four probes can be utilized and the IR drop measured between the two inner probes (see Figure 1). However, both of these configurations leave the chemical potentials of $M$ and $X$ ill defined. It is known that the partial conductivities may be decisively affected by the $M / X$ ratio, which will be established by fixing the chemical potentials. Because of this, it is preferable to fix the $M / x$ ratio by 
Argon gas

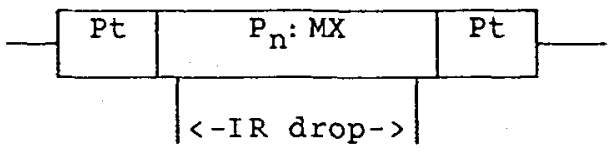

Fig. 1 -- Schematic diagram of electrodes used to measure the ac conductivity of $\mathrm{P}_{\mathrm{n}}$ : $\mathrm{MX}$ either by the two-probe or four-probe technique. The chemical potentials in the polymer electrolyte are not defined.

fixing the chemical potential of one of the two constituents as shown schematically in Figure 2.

Argon gas

(a)

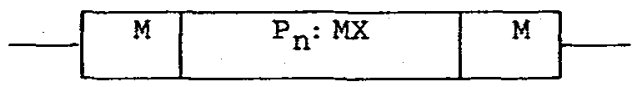

Argon gas

(b)

\begin{tabular}{|c|c|c|}
\hline M-N & $P_{n}: M X$ & $M-N$ \\
\hline alloy & & alloy \\
\hline
\end{tabular}

(c)

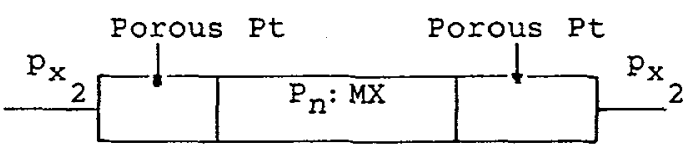

Fig. 2 - - Schematic diagram of electrodes used to fix the M/X ratio in a solid polymer electrolyte, $\mathrm{P}_{\mathrm{n}} \mathrm{MX}$. (a) Electrodes of the parent metal, $M$. (b) Electrodes of an alloy, $M N$, in which $N$ is inert. (c) Electrodes of porous platinum with a coexisting partial pressure of $x_{2}$ gas.

The first diagram in Figure 2 involves symmetric electrodes of the parent metal $M$. These can fix the chemical potential of M. Figure $2 \mathrm{~b}$ shows a setup utilizing an alloy, MN, to fix the chemical potential of $M$ at a value lower than that depicted in Figure $2 a$. Here, $N$ is an inert element. Figure $2 \mathrm{c}$ shows a diagram of electrodes to fix the chemical potential of $M$ at its lowest value. In each of these cases, the electrodes are assumed to be reversible. Using such setups, one can obtain a well-defined value of the total conductivity $\sigma$ as defined above.

A useful electrolyte must behave not only as an ionic conductor but also as an electronic insulator. In practice, this means that the electronic conductivity must be so low $\left(=10^{-9} \mathrm{~S} / \mathrm{cm}\right)$ that the cell would take a very long time, say four years to self-discharge on standing.

In general, the electronic conductivity of an electrolyte should be at least five orders of magnitude lower than the ionic conductivity, which means that the self-discharge current is below $10^{-5}$ of the normal current under load. Polymer electrolytes, unlike many other forms of solid electrolytes, have no difficulty in fulfilling this requirement.

The electronic conductivity arises from current carried by electrons and/or electron holes: 


$$
\sigma_{e l}=\sigma_{e}+\sigma_{h}
$$

It is possible to discriminate between these two contributions by such techniques as the wagner polarisation cell, which is discussed in section 5. The disadvantage of such methods is that test electrodes replace those that would be used in a practical device application and so the behaviour of the electrode-electrolyte interfaces is significantly different. In consequence, the predicted electronic conductivity may be some orders of magnitude higher or lower than that encountered when the electrolyte is incorporated in a working device.

The ionic conductivity of a polymer electrolyte of the type $P_{n}: M X$ would be expected to arise solely from cationic contributions from $\mathrm{M}^{+}$ and anionic contributions from $x^{-}$. For polymer electrolytes where $P$ is poly (ethylene oxide), for which the relative molar mass of the repeat unit is 44 , and $\mathrm{n}$ is typically about 4 to 10 , the concentration of the 'solution' of salt in the polymer is about 2 to $5 \mathrm{M}$. This approaches the concentration found in molten salts.

A feature of the behaviour of such concentrated systems is the preponderance of ion pairs and triple ions. The ionic transport then includes contributions from cations such as $\mathrm{M}_{2} \mathrm{X}^{+}$and anions such as $\mathrm{MX}^{-}$. Most techniques for determining the individual conductivities of different species in fact only discriminate between two classes : those that are reversible at a given non-blocking electrode and those that are not. If the test cell is configured so that the contribution of the cations to the total ionic conductivity can be determined, then the cationic transference number, $\tau_{+}$, can be obtained. This may be defined as:

$$
\tau_{+}=\frac{\sigma_{+}}{\sigma_{i}}=\frac{\Sigma\left(\sigma_{+}\right)_{j}}{\sigma_{i}}=\Sigma\left(t_{+}\right)_{j}
$$

where $\left(\sigma_{+}\right)_{1},\left(\sigma_{+}\right)_{2}$, etc., are the conductivities of the first, second, etc., cationically conducting species. The anionic transference number, $\tau_{-}$, similarly defined, and is related to $\tau_{+}$by:

$$
\tau_{-}=1-\tau_{+}
$$

The term transport number, $t$, is reserved for the contribution of an individual species.

For the polymer electrolyte $\mathrm{P}_{\mathrm{n}}$ : $\mathrm{MX}$, there are separate transport numbers $t\left(M^{+}\right), t\left(M_{2} x^{+}\right)$(and perhaps if water is also present within the electrolyte $\left.t_{\mathrm{H}^{+}}\right)$for each of the individual mobile cation species, but it is easier to determine the sum of these, $\tau_{+}$, than to separate out the speciated values.

\section{Direct-Current Conductivity}

DC conditions using either blocking or non-blocking electrodes give rise to polarisation problems in conductivity measurements. In spite of these pitfalls, the total DC conductivity has routinely been used to characterize polymer electrolytes and a threshold value of approximately $10^{-5} \mathrm{~S} \mathrm{~cm}^{-1}$ has been used as the criterion for possible application purposes. A large number of materials reach such a conductivity value between room temperature and $100^{\circ} \mathrm{C}(3-7)$. Several aspects govern the magnitude of the conductivity, namely the degree of crystallinity, the salt concentration, the nature of the salt and polymer (8). Temperature and pressure have been used in a great number of studies as variables in investigations of those conductivity aspects. 


\section{1 Measurements with Blocking Electrodes}

With blocking electrodes, there is neither a source nor a sink for mobile ions. The migration of the ions under the influence of the electric field therefore leads to an enrichment of the mobile species in the region of the electrolyte adjacent to one electrode and a depletion near the other electrode. The ionic motion is then opposed by a chemical potential gradient and when, after a short time, this has increased sufficiently to counterbalance the electric field, the migration stops. The cell is then said to be concentration polarized.

since the calculation of the cell conductance depends on the assumption of ohmic behaviour, which pertains only at the instant of initial application of the applied voltage, it is difficult to determine conductance accurately from DC measurements on test cells with blocking electrodes.

The mechanism by which current initially flows across a test cell with blocking electrodes under the influence of an applied voltage can be visualised as follows. Neither the electronic charge carriers within the electrode nor the ionic charge carriers within the electrolyte can cross the electrode-electrolyte interface. The applied voltage causes a build-up of negative charge on the electrode side of one of the interfaces. This induces a corresponding build-up of positively charged ions on the electrolyte side of the same interface. A similar 'double layer' of separated charges, but with the signs reversed, is set up at the other interface. The electric field that causes ionic motion within the electrolyte is that caused by the charge concentration gradient from the electrolyte side of the interface.

The double layers each have infinite resistance to the direct passage of charge, but have a capacitance term that results from the layers of separated charge. The double layer can be visualized as a parallel-plate capacitor, and since

$$
c=\epsilon_{0} \epsilon_{r} A / d
$$

(where $\epsilon_{0}$ is the permittivity of free space, $\epsilon_{r}$ is the relative permittivity, $A$ is the area of the plates and $d$ is the distance between them), the capacitance term, $C$, is relatively large (of the order of $\mu \mathrm{F})$ since the separation, $d$, is very small.

The equivalent circuit to the cell is displayed in Figure 3a. The so-called geometric capacitance, $C_{g}$, that appears in parallel is a consequence of the charges on the electrodes themselves. This term would be present even if the electrolyte were to be removed. Its magnitude is small compared with the double-layer capacitance $c_{d l}$, because the intercharge separation is much greater. The electrolyte conductance, G, is the reciprocal of the electrolyte bulk resistance, $\mathbf{R}_{\mathrm{b}}$.

\section{2 Measurements with Non-block1ng Electrodes}

In this case, there is both a source and a sink for the mobile ionic species. As in the case of non-blocking electrodes, however, DC meas urements do not easily provide accurate values for the bulk resistance, $R_{b}$. This is because, although ions can cross the boundary, electrons and/or holes cannot. Since these are the conducting species within the electrodes, the charge-transporting process has to be transferred to and from electrons and ions at the two interfaces.

The kinetics of this charge-transfer process are not infinitely facile, and consequently there is a resistance, $R_{c t}$ associated with 
the charge-transfer process. This results in a build-up of charge on either side of the interface, which produces an associated, and quite large, charge-transfer capacitance, in parallel with the resistance. The equivalent circuit for this situation is similar to that for blocking electrodes, but the double-layer capacitance is shunted by the charge-transfer resistance, as shown in Fig. 3b. A DC measurement, therefore, does not give the value of $R_{b}$ directly.

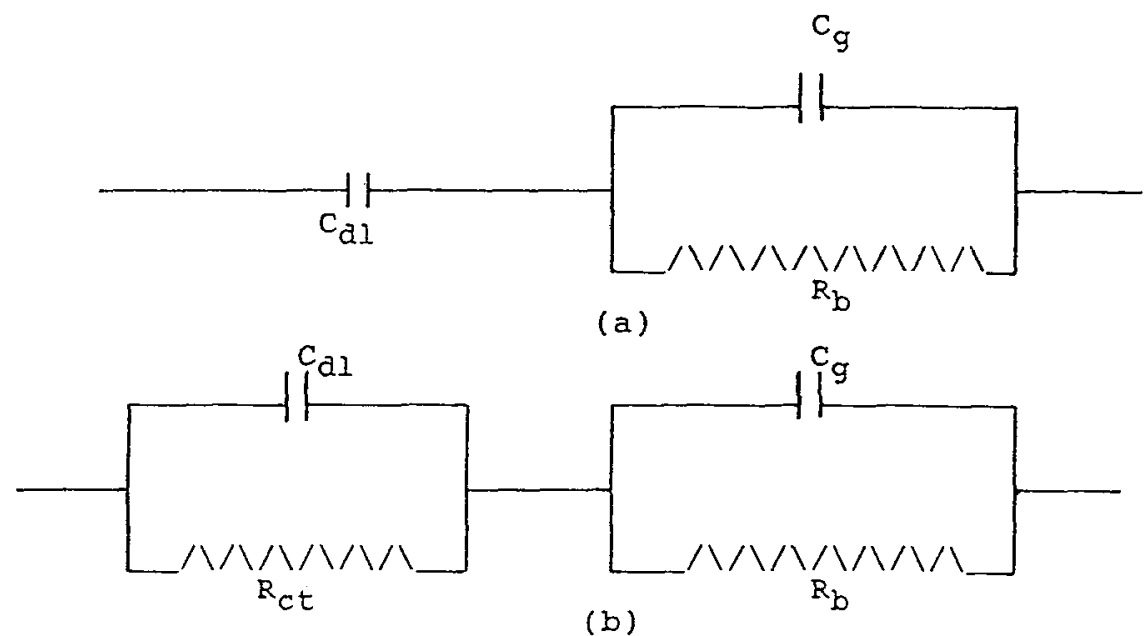

Eig. 3 -- (a) Equivalent circuit for a test cell with blocking elec trodes; (b) equivalent circuit for a test cell with nonblocking electrodes.

\section{3 Factors affecting the Conductivity}

It has been observed for both hydrated and dehydrated salts that isotherms of $\log \left(\sigma / \mathrm{s} \mathrm{cm}^{-1}\right)$ against stoichiometry number, $n$, are usualIY irregular $(9,10)$. Consequently isopleths of $\log \left(0 / \mathrm{s} \mathrm{cm}^{-1}\right)$ against $1000 \mathrm{~K} / \mathrm{T}$ vary in gradient, and may cross each other. In some systems, e. g. , $\mathrm{PEO}_{\mathrm{n}}: \mathrm{Ca}\left(\mathrm{ClO}_{4}\right)_{2} \cdot 6 \mathrm{H}_{2} \mathrm{O}$, the conductivity maximum appears to lie at concentrations of salt that are more dilute (i.e., n>18) than those studied. This apparently curious finding of an inverse relationship between conductivity and salt content is also observed (11) for $\mathrm{PEO}_{\mathrm{n}}: \mathrm{LiClO}_{4}$.

In Table 1, the compositions for maximum conductivity, $\mathrm{n}_{\text {max }}$ are tabulated as a function of temperature for a range of systems.

Inspection of Table 1 reveals that $n_{\text {max }}$ varies substantially with anion, cation and temperature, from below 8 to above 16. The observed limits of the variation, i.e., 4-24, may be artificially narrow and merely reflect the truncated range chosen by individual authors.

values of $n_{m i n}$ are presented in Table 2. Although also irregular, it can be seen that, except for some hydrated salt systems near room temperature, $n_{\min }<n_{\max }$. It is clear that $n_{\max }$ and $n_{\min }$ do not correlate with cationic radius (or charge density), although at certain temperatures it has been noted that conductivity at fixed $n$ decreases with increase in cationic radius (10). As can be seen in Table 3 the conductivity results for $\mathrm{PEO}-\mathrm{X}\left(\mathrm{ClO}_{4}\right)_{2} \cdot 6 \mathrm{H}_{2} \mathrm{O}$ complexes, where $\mathrm{X}=\mathrm{Mg}^{2+}$, $\mathrm{Zn}^{2+}, \mathrm{Ca}^{2+}, \mathrm{Sr}^{2+}$, are in accord with that observation, too. There appears to be some ambiguity regarding the choice of the 
anion that will yield maximum conductivity with a given cation, or vice versa. Further significant observations can be reported, however, as discussed below.

Linford and co-workers (10) have found that the polyether electro-

\section{TABLE 1}

$\mathrm{PEO}_{\mathrm{n}}$ : salt ratios for maximum conductivities

\begin{tabular}{|c|c|c|c|c|c|c|c|c|c|c|c|c|}
\hline \multirow{2}{*}{ Salt } & \multicolumn{11}{|c|}{ Temperature $\left({ }^{\circ} \mathrm{C}\right)$} & \multirow{2}{*}{ Ref. } \\
\hline & 20 & 30 & 40 & 50 & 60 & 70 & 80 & 90 & 100 & 110 & 120 & \\
\hline $\mathrm{Ca}\left(\mathrm{ClO}_{4}\right)_{2} \cdot 6 \mathrm{H}_{2} \mathrm{O}$ & 12 & 12 & 18 & 18 & 18 & 18 & 18 & 18 & 18 & 18 & 18 & 10 \\
\hline $\mathrm{Ca}(\mathrm{SCN}), 3 \mathrm{H}_{2} \mathrm{O}$ & 9 & 9 & 12 & 12 & 15 & 15 & 15 & 15 & 15 & 15 & 15 & 10 \\
\hline $\mathrm{Cu}\left(\mathrm{ClO}_{4}\right)_{2}$ & & 8 & 8 & 8 & 8 & 8 & 8 & 8 & 8 & & & 12 \\
\hline MgCl, 4.2 & & 16 & 16 & 16 & 16 & 16 & 16 & 16 & 16 & 16 & 15 & 9,13 \\
\hline $\mathrm{Mg}\left(\mathrm{ClO}_{4}\right)_{2} \cdot 6 \mathrm{H}_{2} \mathrm{O}$ & 12 & 12 & 12 & 12 & 12 & 15 & 18 & 18 & 18 & 15 & 15 & 10 \\
\hline $\mathrm{Mg}(\mathrm{SCN})_{2} \cdot 4 \mathrm{H}_{2} \mathrm{O}$ & 15 & 18 & 18 & 18 & 18 & 18 & 12 & 12 & 12 & 12 & 12 & 10 \\
\hline $\mathrm{PbBr}_{2}$ & & 8 & 8 & 8 & 8 & 8 & 8 & 8 & 8 & 8 & 8 & 9,14 \\
\hline $\mathrm{Sr}\left(\mathrm{ClO}_{4}\right)_{2} \cdot 6 \mathrm{H}_{2} \mathrm{O}$ & 12 & 12 & 12 & 12 & 12 & 12 & 12 & 12 & 12 & 12 & 12 & 10 \\
\hline $\mathrm{ZnCl}_{2}$ & & 8 & 8 & 8 & 8 & 8 & 4 & 4 & 4 & & & 12 \\
\hline $\mathrm{Zn}\left(\mathrm{ClO}_{4}\right)_{2} \cdot 6 \mathrm{H}_{2} \mathrm{O}$ & 18 & 18 & 18 & 18 & 18 & 18 & 18 & 18 & 18 & 18 & 18 & 10 \\
\hline $\mathrm{PbI}, \quad 4,2$ & & 24 & 24 & 24 & 24 & 24 & 24 & 24 & 24 & 24 & 24 & 14 \\
\hline $\mathrm{PbCl}_{2}$ & & 16 & 16 & 16 & 16 & 16 & 16 & 16 & 16 & 16 & 16 & 14 \\
\hline
\end{tabular}

TABLE 2

$\mathrm{PEO}_{\mathrm{n}}$ : salt ratios for minimum conductivities

\begin{tabular}{|c|c|c|c|c|c|c|c|c|c|c|c|c|}
\hline \multirow{2}{*}{ Salt } & \multicolumn{11}{|c|}{ Temperature $\left({ }^{\circ} \mathrm{C}\right)$} & \multirow{2}{*}{$\operatorname{Ref}$} \\
\hline & 20 & 30 & 40 & 50 & 60 & 70 & 80 & 90 & 100 & 110 & 120 & \\
\hline $\mathrm{Ca}\left(\mathrm{ClO}_{4}\right)_{2} \cdot 6 \mathrm{H}_{2} \mathrm{O}$ & 15 & 15 & 9 & 9 & 9 & 9 & 6 & 6 & 6 & 6 & 6 & 10 \\
\hline $\mathrm{Ca}(\mathrm{SCN}) 2 \cdot 3 \mathrm{H}_{2} \mathrm{O}$ & 6 & 6 & 6 & 6 & 6 & 6 & 6 & 6 & 6 & 6 & 6 & 10 \\
\hline $\mathrm{Cu}\left(\mathrm{ClO}_{4}\right)_{2}$ & & 4 & 4 & 4 & 4 & 4 & 4 & 4 & 4 & 4 & 4 & 12 \\
\hline $\mathrm{Mg}\left(\mathrm{ClO}_{4}^{4}\right)_{2}^{2} \cdot 6 \mathrm{H}_{2} \mathrm{O}$ & 15 & 6 & 6 & 6 & 6 & 6 & 6 & 6 & 6 & 6 & 6 & 10 \\
\hline $\mathrm{Mg}(\mathrm{SCN})^{4}, 4 \mathrm{H}_{2} \mathrm{O}$ & 6 & 6 & 6 & 6 & 9 & 6 & 6 & 6 & 6 & 6 & 9 & 10 \\
\hline $\mathrm{Zn}\left(\mathrm{ClO}_{4}\right)_{2} \cdot 6 \mathrm{H}_{2} \mathrm{O}$ & 9 & 9 & 9 & 9 & 9 & 9 & 9 & 9 & 9 & 9 & 9 & 10 \\
\hline $\mathrm{ZnCl}_{2} 4.2$ & & 12 & 12 & 12 & 12 & 12 & 12 & 12 & 12 & 12 & 12 & 12 \\
\hline $\mathrm{MgCl}_{2}$ & & 4 & 4 & 4 & 4 & 4 & 4 & 4 & 4 & 4 & 4 & 13 \\
\hline $\mathrm{PbBr}_{2}$ & & 16 & 16 & 16 & 16 & 16 & 16 & 16 & 16 & 16 & 16 & 14 \\
\hline $\mathrm{PbI}_{2}{ }^{2}$ & & 16 & 16 & 16 & 8 & 8 & 8 & 8 & 8 & 8 & 8 & 15 \\
\hline
\end{tabular}


TABLE 3

Maximum conductivities of the PEO: salt complexes, in (-log o)values

\begin{tabular}{|c|c|c|c|c|c|c|c|c|c|c|c|c|}
\hline \multirow{2}{*}{ Salt } & \multicolumn{11}{|c|}{ Temperature $\left({ }^{\circ} \mathrm{C}\right)$} & \multirow{2}{*}{ Ref. } \\
\hline & 20 & 30 & 40 & 50 & 60 & 70 & 80 & 90 & 100 & 110 & 120 & \\
\hline $\begin{array}{l}\mathrm{Ca}\left(\mathrm{ClO}_{4}\right)_{2} \cdot 6 \mathrm{H}_{2} \mathrm{O} \\
\mathrm{Ca}(\mathrm{SCN})_{2} \cdot 3 \mathrm{H}_{2} \mathrm{O} \\
\mathrm{Cu}\left(\mathrm{ClO}_{4}\right)_{2} \\
\mathrm{MgCl} 2 \\
\mathrm{Mg}\left(\mathrm{ClO}_{4}\right)_{2} \cdot 6 \mathrm{H}_{2} \mathrm{O} \\
\mathrm{Mg}\left(\mathrm{SCN}_{2} \cdot 4 \mathrm{H}_{2} \mathrm{O}\right. \\
\mathrm{PbBr} \\
\mathrm{Sr}\left(\mathrm{ClO}_{4}\right)_{2} \cdot 6 \mathrm{H}_{2} \mathrm{O} \\
\mathrm{ZnCl}{ }_{2} \\
\mathrm{Zn}\left(\mathrm{ClO}_{4}\right)_{2} \cdot 6 \mathrm{H}_{2} \mathrm{O} \\
\mathrm{PbI}_{2} \\
\mathrm{PbCl}_{2}\end{array}$ & $\begin{array}{l}\text { 8. } 0 \\
8.8 \\
4.7 \\
9.4 \\
6.4 \\
9.2 \\
9.0 \\
\text { 5. } 3 \\
\text { 7. } 6 \\
9 \\
9.4\end{array}$ & $\begin{array}{l}\text { 7. } 2 \\
8.2 \\
4.3 \\
8.8 \\
5.6 \\
8.3 \\
8.6 \\
7.5 \\
4.7 \\
6.7 \\
9.6 \\
9.1\end{array}$ & $\begin{array}{l}\text { 6. } 2 \\
7.5 \\
4.0 \\
8.0 \\
5.0 \\
7.0 \\
8.2 \\
6.8 \\
4.4 \\
5.8 \\
9.2 \\
8.7\end{array}$ & $\begin{array}{l}\text { 5. } 2 \\
6.6 \\
3.4 \\
7.2 \\
4.7 \\
6.2 \\
7.8 \\
6.3 \\
4.1 \\
4.9 \\
8.4 \\
8.2\end{array}$ & $\begin{array}{l}4.8 \\
5.8 \\
3.2 \\
6.5 \\
4.3 \\
5.9 \\
7.4 \\
5.7 \\
4.0 \\
4.6 \\
7.4 \\
7.6\end{array}$ & $\begin{array}{l}4.7 \\
5.5 \\
3.0 \\
5.7 \\
4.1 \\
5.6 \\
7.0 \\
5.3 \\
4.0 \\
4.3 \\
6.5 \\
6.7\end{array}$ & $\begin{array}{l}\text { 4. } 4 \\
5.3 \\
3.0 \\
5.5 \\
4.0 \\
5.4 \\
6.0 \\
5.0 \\
3.7 \\
4.0 \\
6.4 \\
6.5\end{array}$ & $\begin{array}{l}\text { 4. } 1 \\
5.2 \\
2.9 \\
5.2 \\
3.9 \\
5.1 \\
5.9 \\
4.7 \\
3.6 \\
3.8 \\
6.3 \\
6.4\end{array}$ & $\begin{array}{l}4.0 \\
5.0 \\
2.8 \\
5.0 \\
3.8 \\
5.0 \\
5.8 \\
4.4 \\
3.4 \\
3.8 \\
6.2 \\
6.3\end{array}$ & $\begin{array}{l}3.9 \\
4.9 \\
4.9 \\
3.7 \\
4.8 \\
5.7 \\
4.2\end{array}$ & $\begin{array}{l}3.8 \\
4.8 \\
4.7 \\
3.6 \\
4.7 \\
5.5 \\
3.9 \\
\text { 3. } 6 \\
5.9 \\
6.2\end{array}$ & $\begin{array}{ll}10 & \\
10 & \\
12 & \\
9, & 13 \\
10 & \\
10 & \\
9, & 14 \\
10 & \\
12 & \\
10 & \\
14 & \\
14 & \end{array}$ \\
\hline
\end{tabular}

lytes of divalent cation perchlorates are generally better conductors than the corresponding thiocyanates. Table 3 shows results for the Mg and $\mathrm{Ca}$ systems confirming this observation, which seems to be also valid for other salts (e.g., the conductivity of PEO: $\mathrm{Mg}\left(\mathrm{ClO}_{4}\right)_{2} \cdot 6 \mathrm{H}_{2} \mathrm{O}$ complexes is higher than the conauctivity of PEO: $\mathrm{MgCl}_{2}$ complexes). The fact that PEO: $\mathrm{Zn}\left(\mathrm{ClO}_{4}\right)_{2} .6 \mathrm{H}_{2} \mathrm{O}$ complexes (10) present lower maximum conductivities than PEO: $\mathrm{ZnCl}_{2}$ complexes (12) may be due to the different preparation procedures of the polymers (different water content trapped in the polymer films), apart from the larger size of the ionic carriers. The hypothesis of ion-pairing between $\mathrm{ClO}_{4}^{-}$and $\mathrm{Zn}^{2+}$ can also be advanced, but evidence for this hypothesis requires experimental confirmation.

As $f a r$ as the effect of the different anions on the conductivity is concerned, it has been shown that $(9,12-14)$ :

$$
\begin{array}{ll}
\sigma\left(\mathrm{PEO}: \mathrm{PbBr}_{2}\right)>\sigma\left(\mathrm{PEO}: \mathrm{PbCl}_{2}\right)>\sigma\left(\mathrm{PEO}: \mathrm{PbI}_{2}\right) & \left(\mathrm{T}<60 \mathrm{O}^{\circ} \mathrm{C}\right) \\
\sigma\left(\mathrm{PEO}: \mathrm{PbBr}_{2}\right)=\sigma\left(\mathrm{PEO}: \mathrm{PbI}_{2}\right)>\sigma\left(\mathrm{PEO}: \mathrm{PbCl}_{2}\right) & \left(\mathrm{T}=60{ }^{\circ} \mathrm{C}\right) \\
\sigma\left(\mathrm{PEO}: \mathrm{PbI}_{2}\right)>\sigma\left(\mathrm{PEO}: \mathrm{PbCl}_{2}\right)>\sigma\left(\mathrm{PEO}: \mathrm{PbBr}_{2}\right) & \left(\mathrm{T}=70{ }^{\circ} \mathrm{C}\right) \\
\sigma\left(\mathrm{PEO}: \mathrm{PbBr}_{2}\right)>\sigma\left(\mathrm{PEO}: \mathrm{PbI}_{2}\right)>\sigma\left(\mathrm{PEO}: \mathrm{PbCl}_{2}\right) & \left(\mathrm{T}>700^{\circ} \mathrm{C}\right)
\end{array}
$$

Comparing these sequences with the values of the ionic radii for the ions $\mathrm{Cl}^{-}, \mathrm{Br}^{-}$and $\mathrm{I}^{-}$, it can be concluded that there is no relationship between maximum conductivities and anionic radii.

If we consider a fixed value of $n$, we can see that the increase in conductivity is a direct function of the increase of the cationic mobility. For example, the ionic radii for $\mathrm{Sr}^{2+}, \mathrm{Ca}^{2+}, \mathrm{Zn}^{2+}$, and $\mathrm{Mg}^{2+}$, decrease in the order $\mathrm{Sr}^{2+}>\mathrm{Ca}^{2+}>\mathrm{Zn}^{2+}>\mathrm{Mg}^{2+}$ and the opposite should occur with the corresponding mobilities. Indeed, Table 3 shows that at $30^{\circ} \mathrm{C}$, for example, the maximum conductivity for the corresponding complexes increases in the order: $\mathrm{PEO}_{12}: \operatorname{Sr}\left(\mathrm{ClO}_{4}\right)_{2} \cdot 6 \mathrm{H}_{2} \mathrm{O}$ < $\mathrm{PEO}_{12}: \mathrm{Ca}\left(\mathrm{ClO}_{4}\right)_{2} \cdot 6 \mathrm{H}_{2} \mathrm{O}<\mathrm{PEO}_{12}: \mathrm{Zn}\left(\mathrm{ClO}_{4}\right)_{2} \cdot 6 \mathrm{H}_{2} \mathrm{O}<\mathrm{PEO}_{12}: \mathrm{Mg}\left(\mathrm{ClO}_{4}\right)_{2} \cdot 6 \mathrm{H}_{2} \mathrm{O}$.

An obvious exception to this rule is shown by complexes like 
PEO: $\mathrm{Cu}\left(\mathrm{ClO}_{4}\right)_{2}$ and PEO: $\mathrm{Mg}\left(\mathrm{ClO}_{4}\right)_{2} \cdot 6 \mathrm{H}_{2} \mathrm{O}$. The ionic radius of $\mathrm{Cu}^{2+}$ is higher than that of $\mathrm{Mg}^{2+}$, so the $\sigma_{\mathrm{Mg}}$ complex should be higher than the $\sigma_{C u}$ complex. However, this is not the case, which can easily be understood on the basis of the fact that $\mathrm{Mg}^{2+}$ mobile ions are surrounded by their hydration shells. Moreover, the $\mathrm{Mg}^{2+}$ ions are apparently trapped in strong electrostatic bonds with the ether linkages on the polymer chains.

Papke et al. (16) have found that PEO-alkali metal salt complexes exhibit no detectable crystallisation for the larger cations such as $\mathrm{Rb}^{+}$and $\mathrm{Cs}^{+}$, while $\mathrm{Na}^{+}$salt complexes showed a high degree of crystallinity. A similar observation was noticed for PEO: metal salt complexes with larger anions. Furthermore, Watanabe and Ogata (17) also reported that the larger the cation radius, the higher were the conductivity values for PPO-SCN (alkali metals) electrolytes. Accepting that this phenomenon can be applied to PEO: divalent metal salt complexes also, we can assume that large cations and/or anions favour the production of complexes possessing large proportions of amorphous regions, which explains the higher conductivities obtained experimentally. In fact, the suppression of crystallization improves markedly the transport properties even at ambient temperature where linear PEO is most crystalline, as we have shown recently by synthesizing cell-amorphous interpenetrating polymer networks (18) (Figure 4).

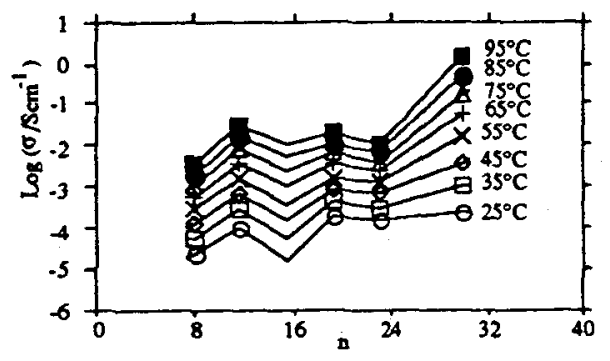
Fig. 4 -- Conductivity as a function of $\mathrm{n}$ in $\mathrm{PEG}_{\mathrm{n}} \mathrm{Mg}\left(\mathrm{ClO}_{4}\right)_{2}$.
From ref. 18 .

For the same complex, at a certain temperature, and variable $n$, we can observe that usualiy the conductivity increases as the salt concentration increases (n decreases), then it attains a maximum for intermediate $n$ values, and finally it decreases for higher salt concentrations. This behaviour is typical of, for example, $\mathrm{PEO}_{\mathrm{n}}: \mathrm{Cu}\left(\mathrm{ClO}_{4}\right)_{2}, \mathrm{PEO}_{\mathrm{n}}: \mathrm{ZnCl}_{2}$ and $\mathrm{PEO}_{n}: \mathrm{MgCl}_{2}$ complexes.

High salt concentrations have four main effects: (a) favour the formation of the PEO: salt complex, leaving a film depleted in free PEO (13); (b) hinder the complete salt dissociation; (c) facilitate the formation of ionic multiplets, such as triplets $\left(X^{-} M^{+} X^{-}, M^{+} X^{-} M^{+}\right)$ and quartets $\left(\mathrm{M}^{+} \mathrm{X}^{-} \mathrm{M}^{+} \mathrm{X}^{-}\right)$, which are less mobile than free ions, and, in addition, decrease their effective concentration (19); (d) diminish the number of vacancies available for ionic transport (20). These effects explain the low conductivities observed at higher salt concentration.

The low conductivities measured at low salt concentrations (n 212 ) are to be expected, due to the reduced number of available charge carriers.

Cation-anion interactions inside the polymer electrolyte, such as the phenomenon of 'ion-pairing' (21), can explain conductivity varia- 
tions over the whole range of temperatures and stoichiometries used. Salts whose anions are large, easily polarizable, and weak Lewis bases, i.e., bases whose conjugate acids are strong, have a reduced tendency for ion-pairing, and their incorporation in the polymeric material leads to higher conductivity complexes. Thus, the concentration dependence of the conductivity is a very complex function, as it is illustrated in Figure 5, which here is for an amorphous interpenetrating polymer network of $\mathrm{PEO}-\mathrm{LiClO}_{4}$ (22).

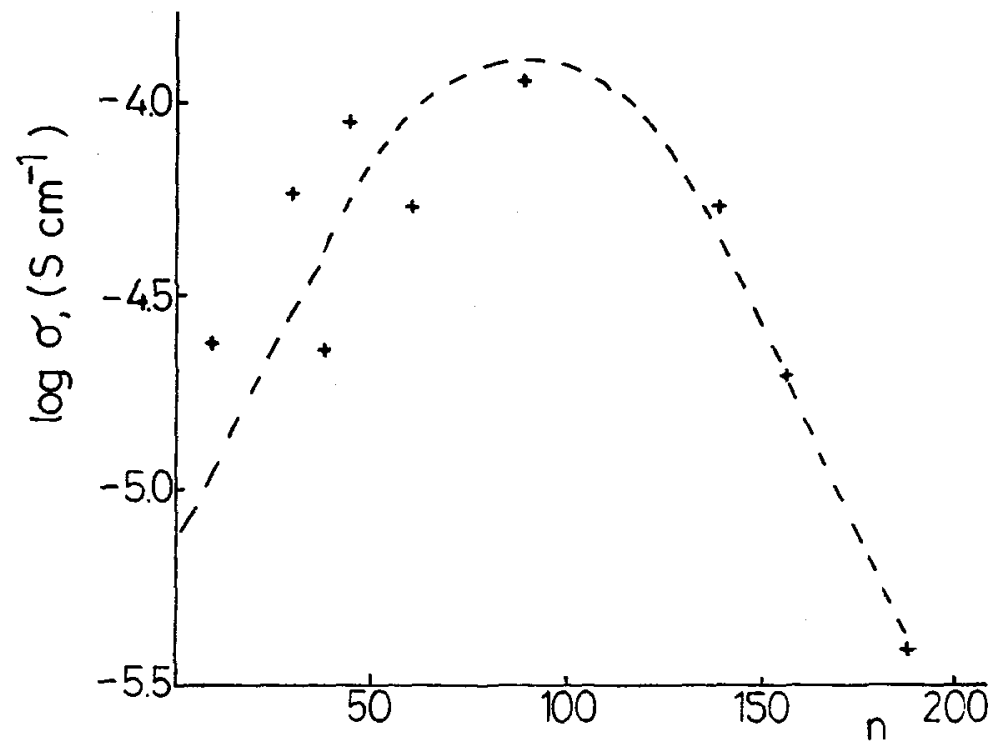

Fig. 5 -- Variation in conductivity with salt concentration for an amorphous interpenetrating polymer network containing $\mathrm{PEO}_{n}: \mathrm{LiClO}_{4}$. From ref. 22.

A number of studies have been carried out where pressure rather than temperature has been used as a variable in investigations of the conductivity. Archer and Armstrong (23) found that the bulk conductivity of a $\mathrm{P}(E O)_{4 .} \mathrm{LiCF}_{3} \mathrm{SO}_{3}$ electrolyte decreased with increasing pressure over the range 60 to $300 \mathrm{MPa}$. When a cell was held at a constant pressure and temperature, the conductivity was again seen to fall with time. These effects were attributed to some form of structural change at higher pressures and may possibly involve increased crystallization (24).

Measurements of transport processes in crystalline solids as a function of pressure allow the activation volume $V^{*}$ for the conduction process to be evaluated. It is defined by (25)

$$
V^{*}=\left(\frac{\delta G}{\delta P}\right)_{T}
$$

where SG represents the free energy change associated with the basic steps in the conduction mechanism. Values of $V^{*}$ can then be used to test theoretical models of the process. This approach has had application in a wide number of solid systems and has been applied to polymer electrolytes by Fontanella and co-workers $(26,27)$ and Chadwick et al. $(28,29)$. Both isobaric and isothermal conductivity studies have been 
carried out. In determining the most appropriate method of association of the free energy change with the ionic conductivity, two options were discussed, one described by an Arrhenius expression, the other by a free volume expression.

Interpreting trends in activation volumes with respect to charge transport is complex. In particular, it has been proposed that factors such as the possession of a permanent dipole by the anion (e.g., trifluoromethanesulfonate or thiocyanate) may have a significant effect on its mobility $(30)$ and thus its contribution to the conductivity.

\section{Alternating-Current Conductivity}

The problems of concentration polarization which complicate DC measurements are largely avoided if an alternating current is used.

$A C$ studies are similar to the DC techniques in that the ratio of voltage to current is measured. For DC, this ratio provides the value of the resistance, $R$, measured in ohms. For AC the ratio gives an analogous quantity, the impedance, $Z$, also measured in ohms. The impedance contains four main contributions; these are from resistance, capacitance, constant phase elements (cpe) and inductance. The last named is unimportant for polymer electrolytes although it can play a role in other electrochemical applications of polymers.

Measurement of the impedance as a function of frequency is called impedance spectroscopy, and the detailed interpretation of this variation provides very important information about the contributions to the test-cell electrochemical behaviour of its various components: interfaces, intra-electrolyte boundaries, and the bulk electrolyte itself. This information is normally extracted by finding anidealized equivalent circuit, the calculated frequency-dependent behaviour of which mimics the actual behaviour of the test cell. The components (resistors, capacitors, etc.) of the equivalent circuit which are networked together in some combination of series and parallel connections can then be identified with parts of the test cell.

The frequency dependence can be displayed in several ways, each of which emphasizes a different frequency regime or a particular contribution. To appreciate these, it is necessary to recognize the fact which is not particularly palatable to the non-mathematically inclined reader, that impedance is a complex quantity. All that this means in practice is that it is made up of two parts; one is called real and is labelled $Z^{\prime}$ and the other is called imaginary and is labelled $2^{\prime \prime}$. The contributions to $z^{\prime \prime}$ are all terms which involve the quantity $j$, the square root of minus one. $Z^{\prime}$ and $Z^{\prime \prime}$ are related to $z$ by:

$$
z=z^{\prime}-j z^{\prime}
$$

The various resistors, capacitors, etc., which are connected to gether in series and parallel combinations to form the equivalent circuit that corresponds to the test cell, contribute to the real and imaginary parts in a way that is quite easy to calculate. The frequency-dependent information can be displayed in the form of $z^{\prime}$ and $z^{\prime \prime}$ as functions of angular frequency, $\Omega$, or of $\log (\Omega)$.

An alternative display, much favoured in the polymer electrolyte field is the so-called complex plane representation, in which $-z^{\prime \prime}$ ( $y-$ axis) is plotted against $Z^{\prime}$ (x-axis). This display is characterized for polymer electrolytes by arcs, which have the form of depressed or flattened semicircles, and straight lines, inclined to the $x$-axis, which are usually called titled spikes. The advantages of this form of data presentation are that each arc or spike is characteristic of a 
particular region of the cell and that the bulk resistance can be easily read from the graph. A disadvantage is that the frequency of each measurement point is not immediately apparent.

The simplest test cell that can be envisaged consist of two blocking electrodes in contact with the polymer whose conductance is to be measured. The three-component equivalent circuit is shown in Fig. $3 a$. The polymer acts as a resistor, $R_{b}$ which is in series with the double-layer capacitor, $c_{d}$, at the interface, and in parallel with the

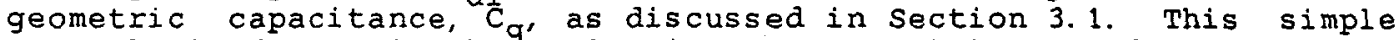
network is dealt with by evaluating the parallel terms first to give an impedance $z_{p}$, which is then added to the double-layer impedance.

This RC parallel combination gives

$$
z_{p}=\frac{R\left(1-j \omega C_{g} R\right)}{1+\left(\omega C_{g} R\right)^{2}}
$$

and the total impedance $z$ is now

so that

$$
z=-\frac{j}{\omega C_{d l}}+\frac{R\left(1-j \omega C_{g} R\right)}{1+\left(\omega C_{g} R\right)^{2}}
$$

and

$$
\mathbf{Z}^{\prime}=\frac{R}{1+\left(\omega C_{g} R\right)^{2}}
$$

$$
z^{\prime}=\frac{\left[1+\left(\omega C_{g} R\right)^{2}\left(1+C_{d l} / C_{g}\right)\right]}{\omega C_{d l}\left[1+\left(w C_{g} R\right)^{2}\right]}
$$

This is already a very complicated expression, although the equivalent circuit was the simplest that could be chosen to represent the physical situation of a conducting cell. The impedance plot is what might be intuitively expected from bringing together a series combination, which produces a vertical spike giving a real-axis value of $R$, and a parallel combination, giving a semicircle tending to the value $R$ at low frequency. The closer the values of $c_{d l}$ and $c_{g}$ (i.e. the thinner the electrolyte), the more the semicircle and the spike tend to merge, as shown in Fig. 6 .

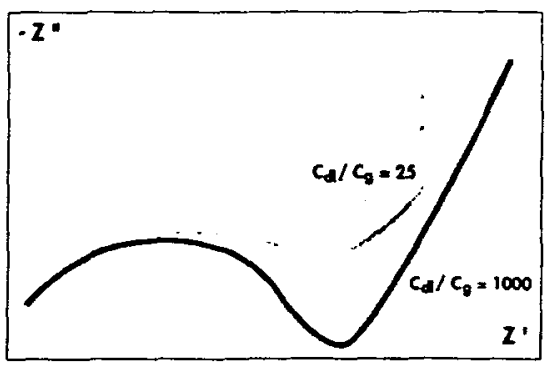

F1g. 6 - The effect of the ratio $C_{a l} / C_{g}$ on the impedance plot.

If the electrodes are non-blocking, then the double-layer capacitance is now shunted in parallel by a charge-transfer resistance, as shown in Fig. $3 b$ and discussed in section 3.2. Evaluation of the 
impedance expression for this equivalent circuit produces two semicircles. The high-frequency semicircle, relates to the bulk electrolyte and the low-frequency semicircle which is further from the origin, arises from interfacial processes. The bulk resistance is the $2^{\prime}$ value at the high-frequency end of the interface semicircle.

Complex impedance plots for the $\mathrm{Ni} / \mathrm{PEO}_{6} \mathrm{NiCl} / 2 / \mathrm{Ni}$ cell recorded at seven different temperatures are shown in Fig. 7 . At temperatures up

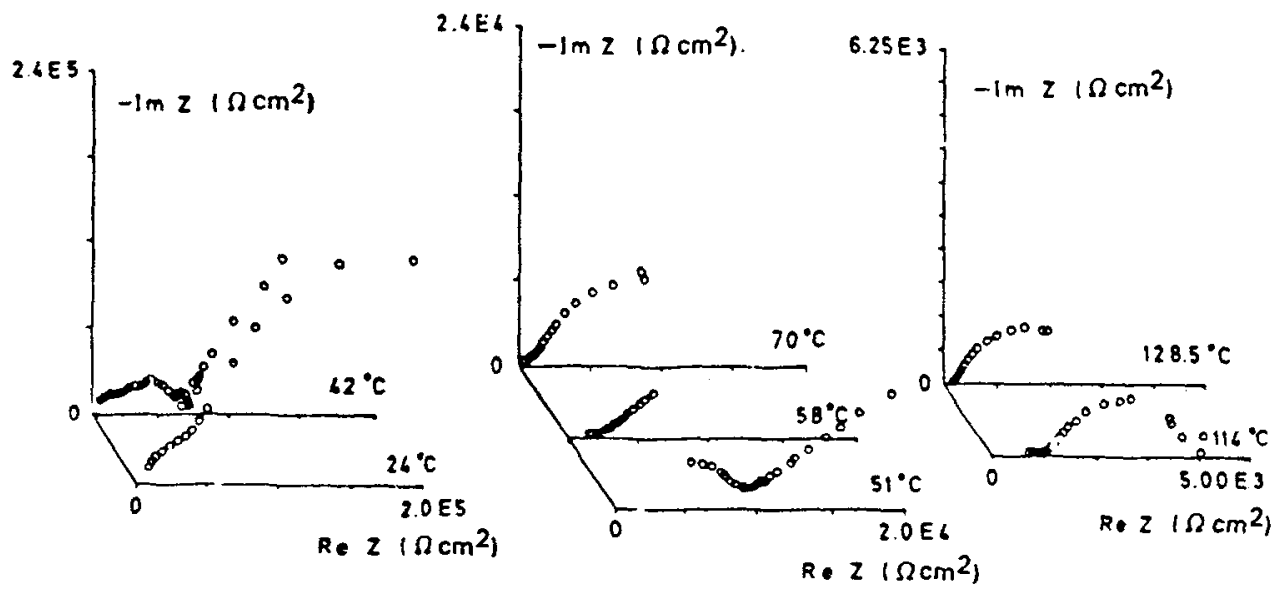

Fig. 7 -- Measured impedances for the cell $\mathrm{Ni} / \mathrm{PEO}_{6} \mathrm{NiCl}_{2} / \mathrm{Ni}$ at seven different temperatures. From ref. 31.

to $50^{\circ} \mathrm{C}$, the system exhibits two semicircles corresponaing to the electrolyte impedance (parallel combination of the geometrical capacity, $\quad C_{g}$ and $R_{b}$, the electrolyte resistance) and to the interfacial impedance (charge transfer resistance, $R_{c f}$, and double layer capacity, $\mathrm{C}_{\mathrm{dl}}$, coupling). For temperatures above $50 \mathrm{~J}_{\mathrm{C}}$, the high frequency semicircle does not appear; this is due to the fact that the corresponding characteristic frequency is higher than $65 \mathrm{KHz}$, the limit of the frequency range for the apparatus used. $R_{b}$ and $R_{c t}$ values also decrease with increasing temperature.

For temperatures from $70^{\circ} \mathrm{C}$ up to $130^{\circ} \mathrm{C}$, the second semicircle, characteristic of intermediate frequencies, almost disappears and a diffusion process is evidenced by an arc with a $45^{\circ}$ high-frequency branch, curving towards the real axis at lower frequencies (see Fig. 7) (31). The value of $w$ at the top of the semicircle related to the bulk electrolyte is given by

$$
\omega=1 / C_{g} R
$$

and it increases substantially as the resistance falls (for example with the temperature of the polymer sample), modifying the usual aspect of the impedance curves for polymer electrolytes. A feature of the impedance plot that is particularly pronounced for polymer electrolytes is the depression of the semicircle and the tilting of the spike. No combination of resistors and capacitors (or inductors) will produce either the depression or the tilting, but both of these are natural consequences of using constant phase elements. Constant phase elements are hybrids between a resistor and a capacitor with an impedance of the form

$$
z_{c p e}=R(\cos [p \pi / 2]-j \sin [p \pi / 2]) / \omega p
$$


where $0 \leq p \leq 1$ and $K$ is a constant.

For a simple circuit consisting of a resistor and a constant phase element in series, the impedance plot is represented by a line, inclined at an angle $p \pi / 2$ to the $Z^{\prime}$ axis and contacting this axis when $Z^{\prime}=R$, as shown in Fig. 8a. For a resistor and a cpe in parallel, a depressed semicircle is produced as shown in Fig. 8b. This cuts the $Z^{\prime}$ axis at the origin and at $Z^{\prime}=R$. Because all angles subtended within $a$ semicircle are right angles, the point $Z^{\prime}=R$ lies vertically above the far end of the diameter of the semicircle. The length of this diameter, $a$, can be seen from Fig. $8 b$ to be given by

$$
\mathrm{d}=\mathrm{R} / \sin [\mathrm{p} \Pi / 2]
$$

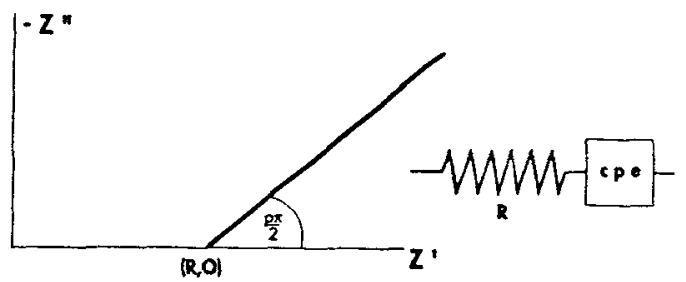

(a)

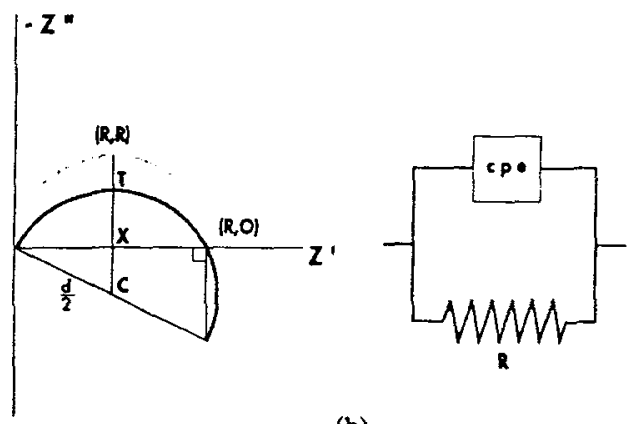

(b)

Fig. 8 -- Impedance representation of the combination of a resistor and a constant phase element (a) in series and (b) in parallel.

and the distance, CT, from the centre to the 'top' of the semicircle is $d / 2$. The height of the top of the semicircle, XT, is clearly CT $\mathrm{XC}$, and since

$$
\mathrm{xC}=(\mathrm{a} \cos [\mathrm{p} \Pi / 2]) / 2
$$

then

$$
\begin{aligned}
X T & =\frac{d}{2}-\frac{d}{2} \cos [p \pi / 2] \\
& =\frac{R(1-\cos [p \Pi / 2])}{2 \sin (p \pi / 2]}
\end{aligned}
$$


The undepressed semicircle resulting from an $R C$ combination in parallel obviously has a top at the point $(R, R)$ and so the depression is $\mathrm{R}-\mathrm{XT}$.

\section{Direct-Current Electronic Conductivity.}

To determine the transport number of the electrons and electron holes in a polymer electrolyte, which may be a factor of $10^{-3}$ or less than that of the ions, the dc polarization method of wagner may be used. In this method, the electrolyte $P_{n}$ : $M X$ is sandwiched between an electrode of the parent metal, $M$, which acts as a reversible electrode, and an ion-bloeking electrode such as graphite or platinum. The ion-blocking electrode can exchange electrons with $P_{n}$ : $M X$ but not ions. A dc potential $E$, below the decomposition potential $E_{d}$, is applied to the asymmetric cell. The positive pole is on the ion-blocking electrode (see Figure 9). Because there is no source or sink of $M$ or $X$ at the ionblocking electrode, at steady state only electrons and holes migrate through the sample of $\mathrm{P}_{\mathrm{n}}: \mathrm{MX}$. For an electrolyte for which $t_{i o n}=$ $t_{\text {cation }} \approx 1$, the relevant equation is

$$
I_{S S}=I_{\theta}+I_{\oplus}=\frac{A R T}{I F}\left\{\sigma_{\theta}{ }^{0}\left[1-\exp \left(-\frac{E F}{R T}\right)\right]+\sigma_{\oplus}^{\circ}\left[\exp \left(\frac{E F}{R T}\right)-1\right]\right\}
$$

where
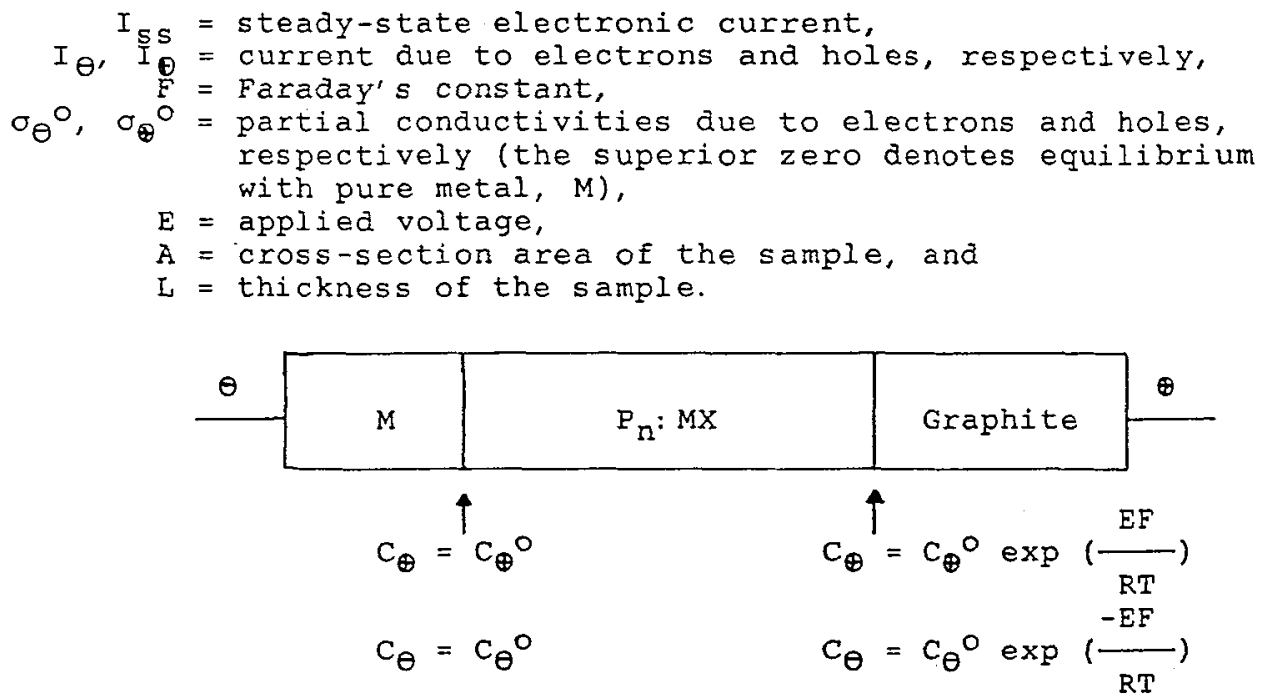

Fig. 9 -- Wagner's dc polarization cell. The negative electrode is a reversible electrode and the activity of $M$ is unity at the $M / P_{n}$ : $M X$ interface. A dc potential $E$ is applied so the activity of $M$ at the $\mathrm{P}_{\mathrm{n}}$ : MX|ion-blocking electrode interface is $\exp (-\mathrm{EF} / \mathrm{RT})$ at steady state. Boltzmann statistics or an ideal solid solution are assumed for the electrons and electron holes in $\mathrm{P}_{\mathrm{n}}$ : MX. The concentration of electrons and electron holes are denoted by $c_{\theta}$ and $C_{\theta}$, respectively. The super zero denotes that the concentration in $P_{n}$ : $M$ is at equilibrium with $M$.

A schematic diagram of I-E curve for such a polarized cell is shown 
in Figure 10. Generally, the equation for $I_{s s}$ may be simplified, yielding

$$
\frac{I_{S S}}{1-\exp (-E F / R T)}=\frac{A R T}{L F}\left[\sigma_{\oplus}^{\circ} \exp \left(\frac{E F}{R T}\right)+\sigma_{\theta}{ }^{0}\right]
$$

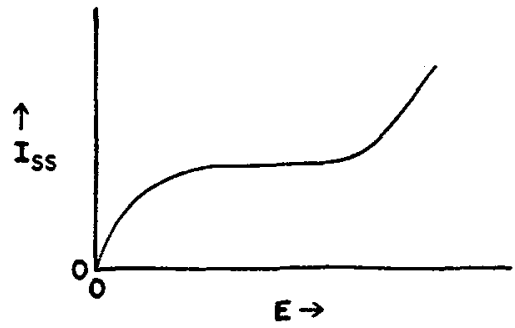

Fig. 10 -- Schematic diagram of Iss versus E for a polarized cell as shown in Figure 9.

from which a plot of $I_{s s} /[1-\exp (-E F / R T)]$ versus exp [EF/RT] yields, in principle, the values of $\sigma_{\Theta}{ }^{\circ}$ and $\sigma_{\Theta}{ }^{\circ}$. However, within each volume element there is equilibrium between the electrons and electron holes; that is the intrinsic constant $k$, is satisfied. Hence, the product $(\theta)(\oplus)$ is very small and $\sigma_{\Theta}{ }^{\circ}, \sigma_{\oplus}{ }^{\circ}$, and $\exp (-E F / R T)$ are small. Accordingly, the plot of the previous equation rarely yields a positive slope and positive intercept within the experimental uncertainty of the data.

The use of ac measurements to obtain the total conductivity and the dc polarization cell to obtain the electronic conductivity allows the separation of ionic and electronic conductivity whose values may differ by many orders of magnitude.

A key feature of the wagner cell methodology is that the activity of the mobile ionic species is controlled at the reversible electrode, and for many polymer electrolytes both anions and cations conduct (8, 31).

It is, therefore, only for polymer electrolytes in which ionic transport is effectively entirely either anionic or cationic that the use of the wagner technique can be usefuliy contemplated.

An alternative to the Wagner technique is the use of transient methods. Electrons and holes respond much more rapidly to fluctuations in applied potential than ions do. A cell of the type M|electrolyte/M has a DC voltage applied across it and the current-time characteristics are monitored as a rapid voltage pulse is superimposed. The response will be rapid for a sample with high electronic conductivity and slow for a good electronic insulator.

\section{Ionic Conductivity}

There are a lot of $A C$ and DC techniques for probing the transport of charged and neutral species. Among them, we can refer the electrolysis method, the concentration cell techniques, and the ionic polarisation cell technique.

The electrolysis method is a study of the change in amount of material in the anode and cathode compartments of a cell. For liquids, 
this is done by the Hittorf method in which concentration changes are measured by titration, subsequent to the passage of a known total amount of charge. The technique has been applied to low molar mass polymer electrolytes by Cameron et al. (32). For solids, this type of technique is known as the Tubandt method, and involves the careful weighing of easily separated, non-adhering discs of electrode and electrolyte material (33). So far, the only type of polymer materials for which adhesion between the cell layers has been successfully avoided are the network crosslinked materials studied by Cheradame and Niddam-Mercier (34). In both the Hittorf and the Tubandt methods, it is necessary to verify that the electrolyte compartment remains unchanged.

The concentration cell techniques involve the use of concentration celis. Bouridah et al. (35) measured the emf of suitable cells under conditions where no current was passed, and obtained the anion transference number from

$$
\tau_{-}=\frac{-F d E_{\operatorname{cell}}}{R T d \ln a}
$$

where $a$ is the activity of the salt. Such measurements require an independent determination of the variation of activity with concentration. To avoid this, later studiesof the voltages of similar cells with and whithout transference were carried out (36).

The ionic polarization cell technique involves transport under a chemical potential and electrical gradient and, therefore, includes the contributions of both charged and neutral species. The AC procedure has been suggested by sorensen and Jacobsen (37) and is based on the theory of MacDonald $(38,39)$ which involves analysis of the ac impedance spectra of the symmetric cell

$$
M\left|P_{n}: M X\right| M
$$

For the idealized case, the equivalent circuit and response of Figure 11 may be anticipated. The high-frequency semicircle is due to cation migration through the bulk and dielectric polarizations. At lower frequencies, a semicircle arises as a result of the charging and discharging of the electrode-electrolyte interface and reactions of the electroactive ion at the electrode interface. At lowest frequencies, the current is affected by concentration gradients that gives rise to diffusion in the electrolyte, and a skewed semicircle that approaches the limiting dc value of the cell impedance is observed.

For fully dissociated electrolytes, the cation transference number $\tau+$ can be evaluated by comparison of the width of the skewed semicircie, $z_{d}$, with the value of the bulk resistance, $R_{b}$ :

$$
\tau_{+}=1 /\left(1+z_{a} / R_{b}\right)
$$

The ac technique has been by far the most widely used method for obtaining transference numbers on polymer electrolytes $(9,13,31,37$, 40, 41), but again the analysis is relevant only when mobile associated species are not present. In addition, electrode phenomena such as finite electrode kinetics or formation of passivating layers are not considered and, as suggested by Fauteux (42) the diffusion responsible for the low-frequency arcs may not be a bulk process but one of the passivating film on the electrode surface which is generally observed when polymer electrolytes are in contact with metaliic lithium. 


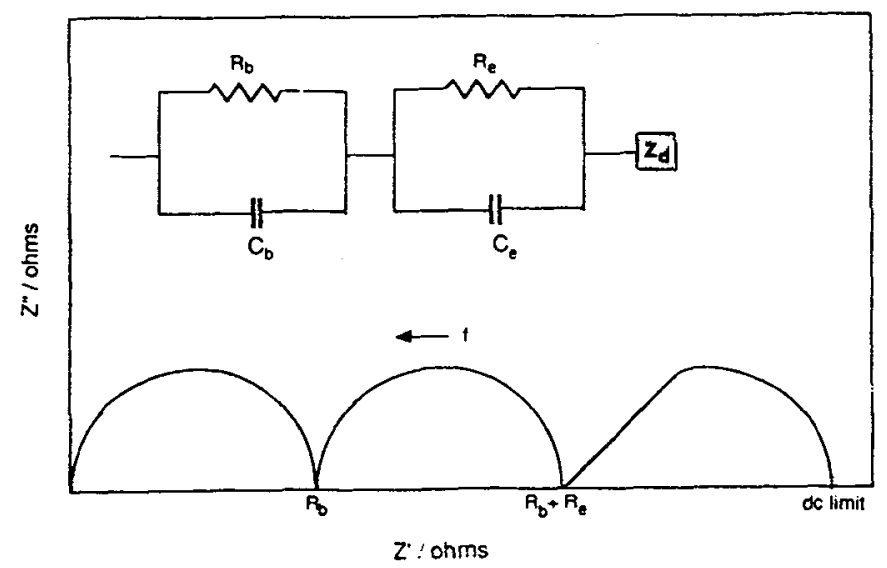

Fig. 11 -- Idealized equivalent circuit and complex plane plot for a polymer electrolyte cell with electrodes that are nonblocking to the cation. $R_{e}$, electrode resistance; $C_{e}$, electrode capacitance; $R_{b}$, electrolyte resistance; $C_{b}$, bulk or geometric capacitance; $z_{d}$, diffusion-controlled impedance.

The preceding considerations have dealt with simpler situations. The effects of nonideality and higher associated charged clusters have yet to be rigorously analyzed and the extent to which the preceeding techniques will lead to results deviated from the real situation remains unanswered.

\section{REFERENCES}

/1/ Sequeira, C. A. C., Port. Electrochim. Acta 3 (1985) 81.

12/ Sequeira, C. A.C. and Marques, F. D. S., Chemtronics 1 (1986) 137.

/3/ Gray, F.M., Solid State Ionics 40/41 (1990) 637.

/4/ Dupon, R., Papke, B. L. , Ratner, M.A. and Shriver, D. F., J. Electrochem. Soc. 131 (1984) 586.

15/ Blonsky, P. M. , Shriver, D. F., Austin, P., and Allcock, H.R., Solid state Ionics $18 / 19$ (1986) 258.

/6/ Chiang, C. K., Davis, G. T. , Harding, C. A., and Takahashi, T., Macromolecules 18 (1985) 825.

/7/ Fang, S., Zhang, P., and Jiang, Y., Polym Bull. 19 (1988) 81.

/8/ Martins, M.A.G. and Sequeira, C. A.C., J. Power Sources 32 (1990) 107.

19/ Yang, L. -L., Huq, R. , Farrington, G. C. and Chiadelli, G., solid State Ionics $18 / 19$ (1986) 291 .

110/ Patrick, A. J. , Glasse, M. D. , Latham, R. J. and Linford, R. G., Solid state Ionics 18/19 (1986) 1063.

111 Neat, R.J., Hooper, A., Glasse, M. D., and Linford, R. G., in F.H. Poulsen, N. Hessel Anderson, K. Clausen, S. Skaarup and 0 . Toft Sorensen (eds.), Transport-structure Relations in Fast Ion and Mixed Conductors, Riso National Laboratory, Roskilde, Denmark, 1985 , p. 341 .

112 / Abrantes, T. M. A., Alcacer, L. J., and Sequeira, C. A. C. , Solid State Ionics $18 / 19$ (1986) 315.

/13/ Yang, L. -L. , McGhie, A. R. and Farrington, G. C. , J. Electrochem. Soc. 133 (1986) 1380 .

/14/ Huq, R., Chiodelli, G. , Ferloni, P., Magistris, A. and 
Farrington, G.C., J. Electrochem. Soc. 134 (1987) 364.

115/ Moryousset, A., Bonnar, M. Fouletier, M. and Hitcher, P., in F.W. Poulsen, N. Hessel Anderson, K. Clausen, S. Skaarup and 0 . Toft Sorensen (eds.), Transport-Structure Relations in Fast Ion and Mixed Conductors, Riso National Laboratory, Roskilde, Denmark, 1985 , p. 335.

/16/ Papke, B. L., Ratner, M. A. and Shriver, D. F., J. Electrochem. Soc. 129 (1982) 1694.

117/ Watanabe, M. and Ogata, N., in J.R. Callum and C. A. Vincent (eds.), Polymer Electrolyte Reviews - 1, Elsevier, London, 1987 , p. 39.

$118 /$ Araújo, I. P. S. and Sequeira, C. A. C. , Proceedings Electrochemical Society Symposium on Fundamentals of Solid Polymer Electrodes and Electrolytes, Honolulu, Hawaii, 1993, Electrochem. Soc., Pennington, N. J. (1993).

/19/ Ratner, M. A., in J. R. MacCallum and C. A. Vincent (eds.), Polymer Electrolyte Reviews - 1, Elsevier, London, 1987, p. 173.

$120 /$ Sequeira, C. A.C. and Hooper, A., Solid State Ionics, 9/10 (1983) 1131.

121 / Papke, B. L. , Dupon, R. , Ratner, M. A., and Shriver, D. F., Solid State Ionics 5 (1981) 685.

122 / Hudson, M. J. and Sequeira, C. A.C., Proceedings Electrochemical Society Symposium on Fundamentals of Solid Polymer Electrodes and Electrolytes, Honolulu, Hawaii, 1993, Electrochem. Soc., Pennington, N. J. (1993).

123/ Archer, W. L. and Armstrong, R. D., Electrochim. Acta 25 (1980) 1689.

/24/ Vincent, C. A., Prog. Solid state Chem. 17 (1987) 145.

/25/ Flynn, C. P. , Point Defects and Diffusion, Clarendon Press, Oxford (1972).

/26/ Greenbaum, S. G., Pak, Y. S., Wintersgill, M. C., Fontanella, J.J., Schulz, J.W. and Andeen, C. G., J. Electrochem. Soc. 135 (1988) 235.

127/ Wintersgill, M. C. , Fontanella, J.J., Smith, M. K. , Greenbaum, S. G., Adamic, K. J., and Andeen, C. J., Polymer 28 (1987) 633.

128 / Chadwick, A.V. , Strange, J.H. and Worboys, M. R., Solid State Ionics $9 / 10$ (1983) 1155.

129/ Bridges, C., and Chadwick, A.V., Solid state Ionics 28-38 (1988) 965.

/30/ Lee, Y. L., and Crist, B., J. Appl. Phys. 60 (1986) 2683.

/31/ Plancha, M. J.C. , Rangel, C. M. and Sequeira, C. A.C., Solid state Ionics 58 (1992) 3.

132 / Cameron, G. C. Harvie, J. I. and Ingram, M. D., Faraday Discussion Chem. Soc. 88 (1989) 55.

/33/ Linford, R. G. and Hackwood, S., Chem. Reviews 81 (1981) 395.

134 / Cheradame, H. and Niddam-Mercier, P., Faraday Discussion Chem. Soc. 88 (1989) 77.

/35/ Bouridah, A., Dalard, F., Deroo, D. and Armand, M. B., Solid State Ionics $18 / 19$ (1986) 287.

/36/ Bouridah, A., Dalard, F. and Armand, M. B., Solid state Ionics $28-30$ (1988) 950 .

/37/ Sorensen, R.R., and Jacobsen, T., Electrochim. Acta 27 (1982) 1671.

/38/ MacDonald, J.R., J. Chem. Phys. 58 (1973) 4982.

/39/ MacDonald, J.R., J. Chem. Phys. 61 (1974) 3977.

$140 /$ PIancha, M. J.C., Rangel, C. M., and Sequeira, C. A. C. , J. Electrochem. Soc. (1993), in press.

/41/ Ferloni, P., Chiodelli, G., Magistris, A. and Sanesi, M., Solid State Ionics $18 / 19$ (1986) 265.

142/ Fauteux, D., Solid State Ionics 17 (1985) 133. 